\section{Repair welding of carbon steel that has been partially graphitized during service}

\section{KJ Kruger*, PGH Pistorius* \& CPM Orsmond ${ }^{* *}$}

*SAIW Centre for Welding Engineering, Department of Materials Science and Metallurgical Engineering, University of Pretoria, Pretoria, South Africa

**Sasol Secunda Synfuels Operations, PdP Kruger Street, Secunda, South Africa

\begin{abstract}
Plain carbon steels that are in service at elevated temperatures (typically $400-450^{\circ} \mathrm{C}$ ) for prolonged periods of time (typically in excess of 20 years) may experience graphitization, often in the heat affected zone (HAZ). This study aimed to determine the effects of HAZ graphite on the mechanical properties of plain carbon steels as well as to characterize the graphite that was observed. Additionally, it was required to evaluate whether repair welding of graphitized material was viable. A combination of gas-tungsten arc welding and shielded metal arc welding was used, in association with various joint configurations. A number of extended heat treatments were performed. Transverse tensile samples did not always fracture through the HAZ graphite. Failure in the graphitized HAZ resulted in a decrease in reduction in area; no other tensile properties were affected by the presence of HAZ graphite. A prediction of the location of the HAZ graphite was developed using the Rosenthal equation. It was demonstrated that it is possible to perform repair welding on graphitized material using conventional welding procedures.
\end{abstract}

Keywords: Carbon steels, graphite, repair, thermal cycling

\section{Introduction}

C-Mn steels are widely used in processes where these materials are exposed to elevated temperatures and pressures for prolonged periods of time. This type of operating environment is typical for pipelines that transport superheated steam. Prolonged exposure (in excess of 20 years) of a carbon-manganese steel steam line to moderately high temperatures (in the range of 400$450^{\circ} \mathrm{C}$ ) resulted in a microstructural change known as secondary graphitization. Secondary graphitization has been the cause of several catastrophic failures, the most notable of which was that of the Springdale Generation Station in the USA in 1943 when a high temperature steam pipe failed due to graphitization [1].

It is generally accepted that the presence of graphite reduces the tensile strength, ductility, and hardness of conventional C-Mn steels such as SA515 Gr 65 [2].

\section{Graphitization}

Graphite formation in carbon steel is classically defined as the decomposition of the metastable cementite phase to form stable ferrite and graphite [3]. It has been demonstrated that steels with the same chemical composition, but different microstructures (induced through heat treatment) prior to graphitization exhibits a rate of graphitization that may vary significantly [4]. This observation indicates that the rate of graphitization is likely determined by the stability of the carbides present in the steel. Much of the early literature reports successful attempts to graphitize various steels using prolonged heat treatments at temperatures ranging from 600 to $760^{\circ} \mathrm{C}$ [4][5][6][7][8].

Secondary graphite manifests in steels in two ways as seen in Figure 1 [9]:

1. Random nucleation of graphite throughout the base metal.

2. HAZ graphite, heterogeneously nucleated along the heat affected zone of welded joints.

The service temperature often determines whether graphitisation or spheroidisation occurs. Figure 2 illustrates that for a particular steel, the transition temperature where spheroidisation becomes more favoured than graphitization is at approximately $540^{\circ} \mathrm{C}$. This transition temperature is difficult to determine and it is unclear which factors determine the transition temperature [12].

Theories on the formation of graphite in the $\underline{\text { HAZ }}$

As can be seen in Figure 1, graphite forms in a very narrow band near the extremity of the HAZ. There are many theories surrounding the nucleation and growth of graphite in the HAZ. Several theories will briefly be discussed.

Heterogeneous nucleation of graphite in the intercritical HAZ (ICHAZ) was proposed to be linked to the aluminium content of the steel. It was suggested that during the weld thermal cycle, the low solubility of aluminium in austenite caused the 
aluminium to segregate to grain boundaries in the ICHAZ where it would serve as nucleation sites for preferential graphitization [10].

An alternative theory exists that suggests that the nucleation sites forms at a position in the HAZ that correlates to temperatures below the $\mathrm{Ac}_{1}$. These sites are reported to form from isolated carbides or cementite in pearlite [11].

It is the authors' interpretation that it is possible that HAZ graphitization occurs first as a result of the decomposition of carbides other than $\mathrm{Fe}_{3} \mathrm{C}$ that were formed during the weld thermal cycle. The rapid decomposition (rapid relative to that of $\mathrm{Fe}_{3} \mathrm{C}$ ) results in a larger number of graphite nucleation sites (being anything from ferrite-ferrite grain boundaries, the ferrite-cementite interface and/or inclusions) becoming active and thus a greater number of graphite nodules form in the HAZ. This explains the larger number of nodules in the HAZ that are in general significantly smaller than those observed in the base metal. Once the rapidly decomposing carbides (relative to that of $\mathrm{Fe}_{3} \mathrm{C}$ ) have been depleted, nodule growth progresses in a manner similar to that of the base metal graphite, where nodule growth is now solely dependent on the decomposition of $\mathrm{Fe}_{3} \mathrm{C}$ and subsequent diffusion of the carbon to the graphite nodules.

Figure 3 highlights the specific and relatively consistent position that HAZ graphitization is observed, typically 200 to $500 \mu \mathrm{m}$ outside of the visible HAZ.

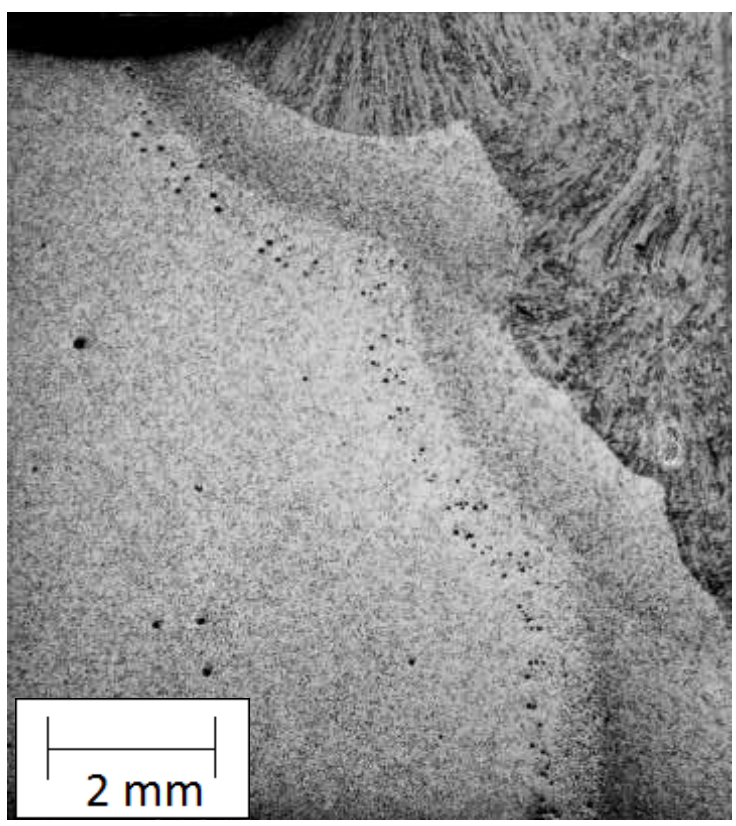

Figure 1: HAZ graphite forming along the low temperature HAZ of a welded joint. [12]

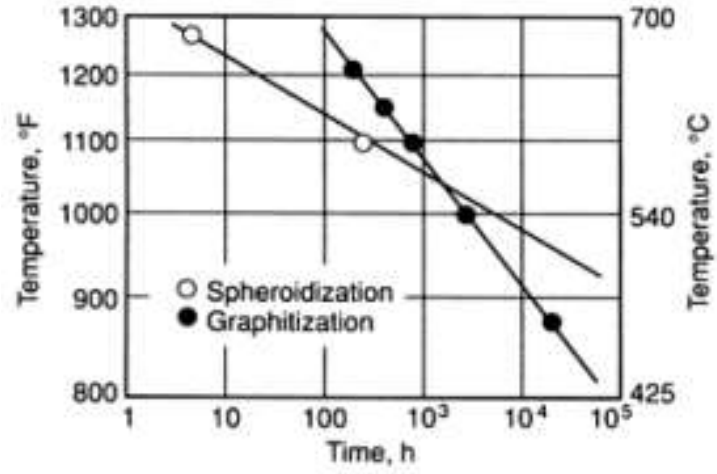

Figure 2: Time taken for half of the carbon in a $0.15 \% \mathrm{C}$ steel to spheroidise compared to time taken for half the carbon in a carbon $-0.5 \%$ Mo steel to graphitise [13].

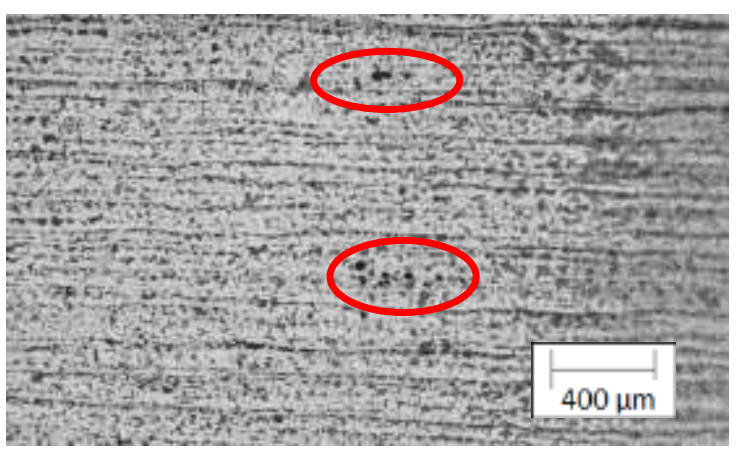

Figure 3: Optical micrograph of graphite that has formed in the $\mathrm{HAZ}$ of $\mathrm{C}-\mathrm{Mn}$ steel after 35 years of service at $420^{\circ} \mathrm{C}$

Figure 4 is a high resolution SEM image of a graphite nodule. It must be noted that such a nodule does not exclusively contain graphite but also ferrite.

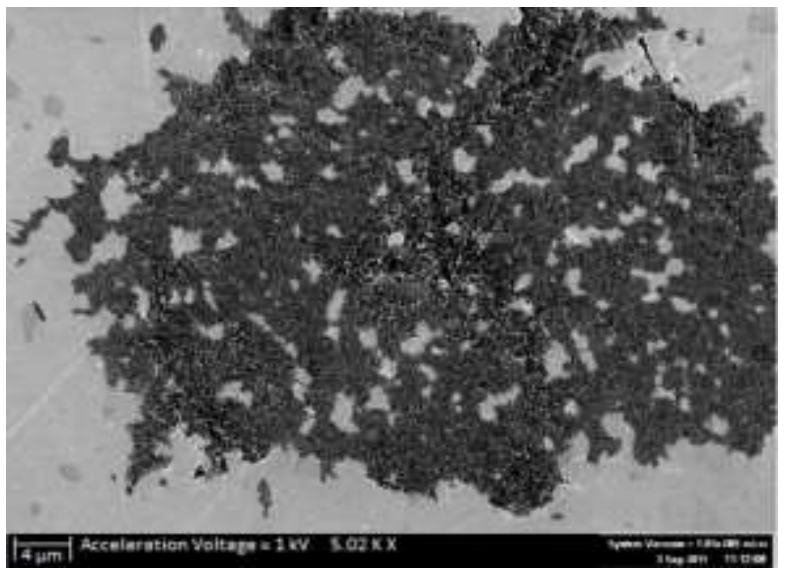

Figure 4: High resolution SEM image of a large base metal graphite nodule

\section{Effect of graphite on mechanical properties}

Graphite was the reported cause of several failures of high temperature pressurised pipelines and was considered to have a negative effect on the 
mechanical properties of hypo-eutectic steels by negatively affecting the tensile strength, ductility and creep resistance [2]. The severity of the decline of mechanical properties associated with graphite was strongly linked to the geometry and concentration of the graphite. Homogeneously nucleated particles of graphite (nodules) are generally considered to have little to no effect on mechanical properties and are rarely a concern [14]. Heterogeneously nucleated graphite nodules was reported to have a severe effect on the mechanical properties of weld heat affected zones. Despite these claims, very little quantitative evidence has been presented to support these claims.

\section{Experimental procedures}

The objective of this study was to characterise the HAZ graphite as well as to identify the effects of HAZ graphite on the mechanical properties of hypoeutectic steels and develop possible repair welding techniques that can be used to refurbish aging $\mathrm{C}-\mathrm{Mn}$ steel pipelines that contain HAZ graphite.

The base material was a section of pipe $(35 \mathrm{~mm}$ thickness) that was in service for 35 years at an average temperature for $427^{\circ} \mathrm{C}$. The base metal conformed to mechanical and chemical properties of SA-515 Gr 65 with a chemical composition as reported in Table 1. The material was removed from service during routine maintenance and contained a circumferential weld with significant amounts of HAZ graphite on both sides of the weld.

Table 1: Chemical composition of the base metal used in the current study

\begin{tabular}{|c|c|c|c|c|c|c|}
\hline$\% \mathrm{C}$ & $\% \mathrm{Mn}$ & $\% \mathrm{Si}$ & $\% \mathrm{Al}$ & $\% \mathrm{~S}$ & $\% \mathrm{P}$ & $\% \mathrm{Fe}$ \\
\hline 0.25 & 0.85 & 0.19 & 0.01 & 0.03 & 0.05 & $\mathrm{Bal}$ \\
\hline
\end{tabular}

During the current study, several weld configurations were evaluated:

- The original material containing the graphitized HAZ.

- A new butt weld that had been welded on homogeneously graphitized base metal.

- A partial penetration double grooved weld which intersected the existing graphitized HAZ.

The rationale behind the half-thickness groove preparation was to create two new heat affected zones, free from graphite, on the outside surface of the pipe. The advantage of this repair technique is that the pressure envelope is maintained. The disadvantage of the half-groove technique is that the graphitised heat affected zone at and close to the inside surface remains intact. A similar repair technique was proposed by Thielsch where all of the HAZ except for a thin ligament is removed mechanically and filled in using conventional welding procedures[15].

All experimental welds were heat treated before, after, or both before and after welding at $635^{\circ} \mathrm{C}$ for $500 \mathrm{~h}$ in an attempt to induce accelerated graphitization and mimic long term exposure to steam temperature. This temperature was selected to be on the low end of previously published graphitization temperatures, that is 600 to $760^{\circ} \mathrm{C}$ [4][5][6][7][8].

Figure 5 and Figure 6 depict the joint configuration prior to welding on the graphitized base metal and graphitized HAZ regions respectively.

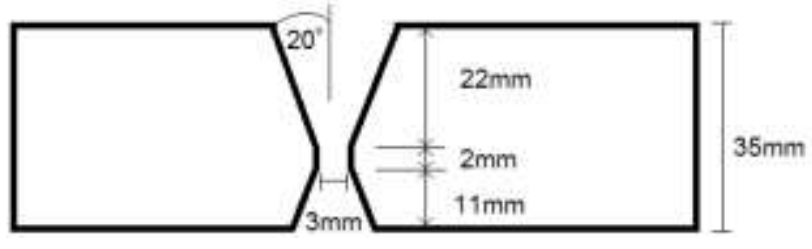

Figure 5: Full thickness groove preparation for graphitized carbon steel (joint preparation for samples 1 and 2).

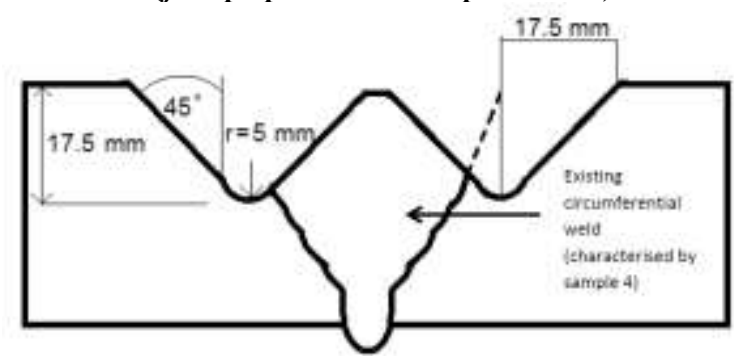

Figure 6: Half thickness groove preparation machined around pre-existing circumferential groove weld (sample 3)

\section{Gas Tungsten Arc Welding (GTAW)}

GTAW was used in samples $1 \& 2$ for the root pass, typical of industrial practice. $2.4 \mathrm{~mm}$ Tungsten-2\% $\mathrm{ThO}_{2}$ electrode, $2.4 \mathrm{~mm}$ diameter ER70S-6 rod and 99.9\% Ar shielding gas was used. The heat input was in the range of 1 to $2 \mathrm{~kJ} . \mathrm{mm}^{-1}$. Preheat and interpass temperatures of $150^{\circ} \mathrm{C}$ and $280^{\circ} \mathrm{C}$ respectively were maintained.

\section{Shielded Metal Arc Welding (SMAW)}

SMAW was used in samples $1,2 \& 3$ to fill the joint and mimic the original welding conditions that were presumably used during initial installation of the pipeline. $3.15 \mathrm{~mm}, 4 \mathrm{~mm}$ and 5 mm diameter E7018-1 electrodes were used. The heat input varied between 1 and $3 \mathrm{~kJ} \cdot \mathrm{mm}^{-1}$. As with the GTAW root pass, preheat and interpass temperatures were $150^{\circ} \mathrm{C}$ and $280^{\circ} \mathrm{C}$ respectively. 
All welding parameters were recorded and the heat input was calculated for each run. All completed welds were evaluated using ultrasonic testing (UT) prior to cutting and machining of test samples. No weld defects were detected during the UT examination. See Table 2 for details of the different welded joints.

Table 2. Welded joints evaluated during current study

\begin{tabular}{|c|c|c|c|c|}
\hline $\begin{array}{l}\text { Sample } \\
\text { number }\end{array}$ & $\begin{array}{c}\text { Heat } \\
\text { treatment } \\
\text { before } \\
\text { weld }\end{array}$ & $\begin{array}{l}\text { Joint } \\
\text { design }\end{array}$ & $\begin{array}{l}\text { Welding } \\
\text { processes }\end{array}$ & PWHT \\
\hline 1 & $\begin{array}{c}600 \mathrm{~h} \text { at } \\
635^{\circ} \mathrm{C}\end{array}$ & $\begin{array}{l}\text { Double V- } \\
\text { groove }\end{array}$ & $\begin{array}{l}\text { GTAW, } \\
\text { SMAW }\end{array}$ & $\begin{array}{c}600 \mathrm{~h} \text { at } \\
635^{\circ} \mathrm{C}\end{array}$ \\
\hline 2 & $\begin{array}{c}600 \mathrm{~h} \text { at } \\
635^{\circ} \mathrm{C}\end{array}$ & $\begin{array}{l}\text { Double V- } \\
\text { groove }\end{array}$ & $\begin{array}{l}\text { GTAW, } \\
\text { SMAW }\end{array}$ & $\begin{array}{l}12 \mathrm{~h} \text { at } \\
635^{\circ} \mathrm{C}\end{array}$ \\
\hline 3 & None & $\begin{array}{c}2 \text { single } \\
\text { V-grooves }\end{array}$ & SMAW & $\begin{array}{c}600 \mathrm{~h} \text { at } \\
635^{\circ} \mathrm{C}\end{array}$ \\
\hline 4 & None & None & None & None \\
\hline
\end{tabular}

The samples were tested in accordance to ASME IX, that is, two transverse tensile tests (with a rectangular cross section) and four transverse side bend tests were machined from each weld [16]. The rectangular cross section tensile tests were supplemented with round tensile tests, for reliable observation of the plastic flow after necking, and measurement of the reduction in area. Other tests included hot tensile tests (at $427^{\circ} \mathrm{C}$ ), hardness profiles using the Vickers microhardness test with a $1 \mathrm{~kg}$ load $\left(\mathrm{HV}_{1}\right)$ as well as weld metal and HAZ Charpy impact tests at $25^{\circ} \mathrm{C}$. Extensive microstructural evaluation was performed using optical and scanning electron microscopy.

\section{Results and discussion}

The results of the tensile test can be seen in Table 3 (rectangular cross section) and in Table 4 (round cross section). In most cases, the tensile test samples failed in the base metal, with a reduction in area of between 69 and 74\% (Table 3 and Table 4). When the fracture surface intersected HAZ graphite, the reduction in area was reduced to $44 \%$ (Table 4). Both full section tensile tests of the sample 4 (as received) failed along the HAZ graphite plane - Figure 7. Image analysis revealed that up to $55 \%$ of the fracture surface of this sample was covered in graphite. Despite the tensile test of sample 4 showing a low reduction in cross sectional area, microscopic evaluation of the steel ligaments separating the graphite nodules appear ductile as seen in Figure 10. It should be noted that the other tensile properties (excluding the reduction in area) of this sample was similar to that of other samples, that did not fail through the HAZ graphite (Table 3).
The impact test samples were removed in the manner described in ASME VIII Div 1 Section UG84(g) (1-2) which states that the Charpy impact sample shall be removed in the transverse direction relative to the weld. For HAZ impact samples, the notch shall be cut approximately normal to the material surface and located such that as much HAZ material as possible is sampled. In the current study, the Charpy notch was placed approximately $5 \mathrm{~mm}$ from the fusion line with respect to the centre of the machined sample. The position of the notch implied that the crack tip sampled various regions of the HAZ, including potential graphitized regions. It is likely that the crack tip did not exclusively sample potentially graphitized HAZ material. Impact toughness was, on average, 218 joules for the weld metal. The average HAZ toughness was $137 \mathrm{~J}$. No other mechanical properties (such as the hot tensile strength, the bend angle, or the hardness) were affected by the presence of HAZ graphite.

Table 3: Tensile results, as measured using transverse tensile samples with a rectangular cross section

\begin{tabular}{|c|c|c|c|}
\hline $\begin{array}{c}\text { Sample } \\
\text { number }\end{array}$ & $\begin{array}{c}\text { Yield } \\
\text { strength } \\
\text { (MPa) }\end{array}$ & $\begin{array}{c}\text { Tensile } \\
\text { strength } \\
\text { (MPa) }\end{array}$ & $\begin{array}{c}\text { Location of } \\
\text { failure }\end{array}$ \\
\hline \multirow{2}{*}{1} & 263 & 410 & PM $^{1}$ \\
\cline { 2 - 4 } & 245 & 416 & PM \\
\hline \multirow{2}{*}{2} & 268 & 416 & PM \\
\cline { 2 - 4 } & 269 & 418 & PM \\
\hline \multirow{2}{*}{3} & 259 & 418 & PM \\
\cline { 2 - 4 } & 277 & 419 & PM \\
\hline \multirow{2}{*}{4} & 272 & 451 & HAZ \\
\cline { 2 - 4 } & 277 & 450 & HAZ \\
\hline
\end{tabular}

1. Parent metal

Table 4: Tensile results, as measured using transverse tensile samples with a round cross section

\begin{tabular}{|c|c|c|c|}
\hline $\begin{array}{c}\text { Sample } \\
\text { number }\end{array}$ & $\begin{array}{c}\text { Tensile } \\
\text { strength } \\
(\mathbf{M P a})\end{array}$ & $\begin{array}{c}\text { Reduction } \\
\text { in area } \\
(\boldsymbol{\%})\end{array}$ & $\begin{array}{c}\text { Location of } \\
\text { failure }\end{array}$ \\
\hline \multirow{2}{*}{1} & 407 & 70 & PM \\
\cline { 2 - 4 } & 410 & 69 & PM \\
\hline \multirow{2}{*}{2} & 420 & 70 & PM \\
\cline { 2 - 4 } & 412 & 71 & PM \\
\hline \multirow{2}{*}{3} & 415 & 70 & PM \\
\cline { 2 - 4 } & 412 & 44 & HAZ \\
\hline \multirow{2}{*}{4} & 452 & 74 & PM \\
\cline { 2 - 4 } & 447 & 69 & PM \\
\hline
\end{tabular}

As stated previously, the purpose of performing round tensile tests was to obtain a more accurate result for total reduction in cross sectional area. One of the round sample 3 tensile tests failed through the graphitized HAZ. The HAZ failure of sample 3 was due to the machining of the sample taking place at a location where the original graphitized HAZ was still intact - and was in fact the only section in the gauge length that was comprised of base metal and not weld metal. The 
tensile strength of sample sets 3 and sample 4 was similar, whether failure occurred in the HAZ or the parent metal. It is therefore considered likely that the failure of the graphitized HAZ only becomes an active factor once necking begins.

The tensile test results showed that all samples that experienced a prolonged heat treatment displayed a reduction in tensile strength of 30 to $40 \mathrm{MPa}$. The reduction in tensile strength can be explained by pearlite spheroidisation during prolonged exposure at $635^{\circ} \mathrm{C}$ - Figure 8 . All samples that experienced the prolonged heat treatment were spheroidised. No graphitization during the extended heat treatment at $635^{\circ} \mathrm{C}$ was observed, consistent with the published work ([13], Figure 2).

A cross section of the graphitized fracture surface can be seen in Figure 9 and Figure 10. By following the curve of the pearlite bands in Figure 10 near the fracture surface, it can be seen that the material appears to undergo localized plastic deformation along the free edges generated by the graphite clusters. The graphite which are the dark clusters observed in these images are confirmed to be graphite through energy dispersive spectroscopy (EDS). The presence of clusters of graphite forces narrow bands of material (100-150 $\mu \mathrm{m}$ broad) to undergo localized necking caused by delamination in the regions between the graphite clusters. It can also be seen that large clusters of graphite still remain intact. These clusters were not intersected by the fracture surface. This suggests that the graphite clusters only participate in the crack propagation if the crack comes into contact with a nodule during its normal progression through the material during failure. The crack typically does not deflect from its normal path (normal assuming no graphite is present) towards the graphite clusters.

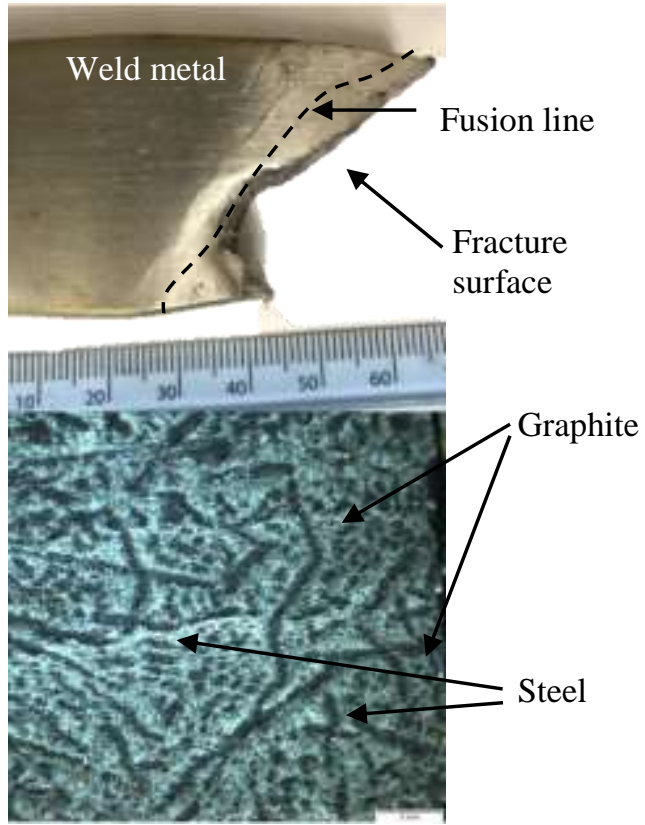

Figure 7: Failure of sample 4 through the graphitized HAZ. a) fracture profile in relation to weld metal. b) Fracture surface (original magnification $8 \mathrm{x}$ ).

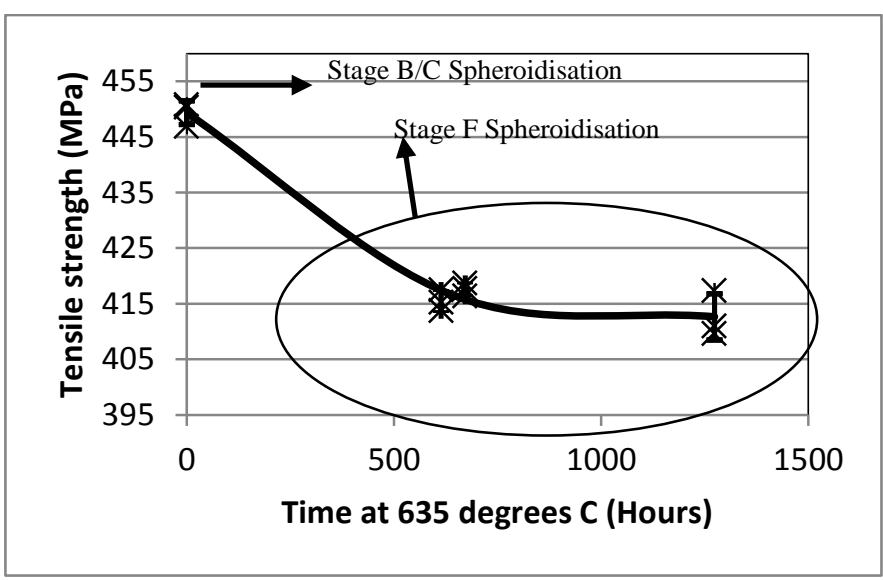

Figure 8: Effects of prolonged heat treatment $\left(\right.$ at $\left.635^{\circ} \mathrm{C}\right)$ on the tensile strength of materials. Degree of spheroidisation as described by Toft and Marsden [17].

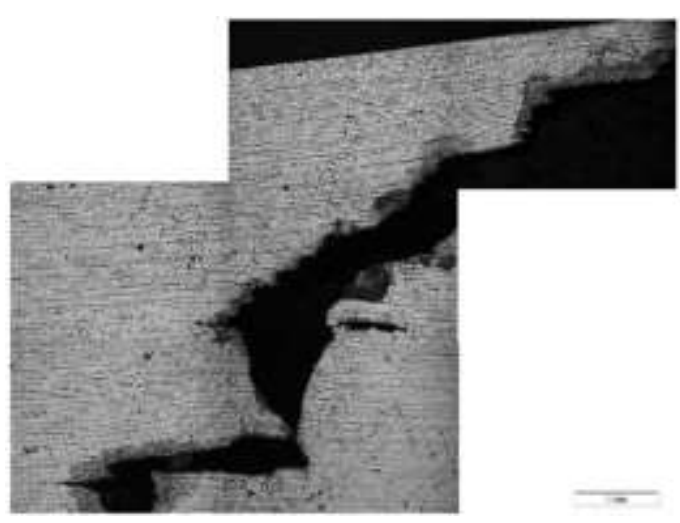

Figure 9: Step-like fracture of rectangular tensile test coupon transverse to as-received circumferential weld (sample 4) 


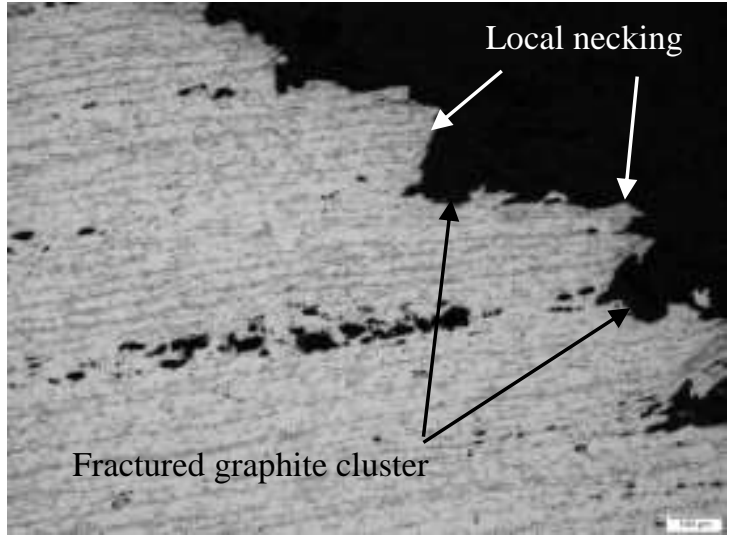

Figure 10: Higher magnification image of fracture surface visible in the previous image (sample 4)

One of the dominant features of HAZ graphite is that it is present in a defined band, some distance from the fusion line. See, for example, Figure 1 and Figure 15. It was suggested by Thielsch [12] that HAZ graphitisation occurs in the intercritical region of the heat affected zone, that is, the part of the welded joint exposed to a peak temperature between the $A_{1}$ and the $A_{3}$ temperature. This explanation of the position of HAZ graphite was evaluated using the Rosenthal equation [18].

The Rosenthal equation, relating temperature to the distance from the weld centreline, for welding of thick plate can be seen in Equation 1.

$$
\begin{array}{ll}
T-T_{0}= & \frac{q / v}{2 \pi \lambda t} e^{-r^{2} / 4 a t} \quad\{1\} \\
\mathrm{T} & =\text { instantaneous temperature }(\mathrm{K}) \\
\mathrm{T}_{0} & =\text { preheat temperature }(433 \mathrm{~K}, \\
& \left.160^{\circ} \mathrm{C}, \text { typical preheat temperature }\right) \\
\mathrm{q} / \mathrm{v} & =\text { heat input }\left(1.8 \times 10^{6} \mathrm{~J} \cdot \mathrm{m}^{-1}, 1.8 \mathrm{~kJ} \cdot \mathrm{mm}^{-1}\right) \\
\lambda & =\text { thermal conductivity }\left(41 \mathrm{~J}^{-1} \cdot \mathrm{s}^{-1} \cdot \mathrm{K}^{-1}\right) \\
\mathrm{a} & =\text { thermal diffisivity }\left(9.1 \times 10^{-6} \mathrm{~m}^{2} \cdot \mathrm{s}^{-1}\right) \\
\mathrm{r} & =\text { radial distance from heat source } \\
& \quad(0.0126 \mathrm{~m}) \\
\mathrm{t} & =\text { time }(\mathrm{s})
\end{array}
$$

This version of the Rosenthal equation can be used to model important aspects of arc welding such as the time material at a fixed distance from the heat source remains above the $\mathrm{Ac}_{1}$ temperature. Figure 11 is an example of the weld thermal cycle calculated using the thick-plate Rosenthal equation to determine the temperature response of carbon steel with respect to time with the parameters shown above.

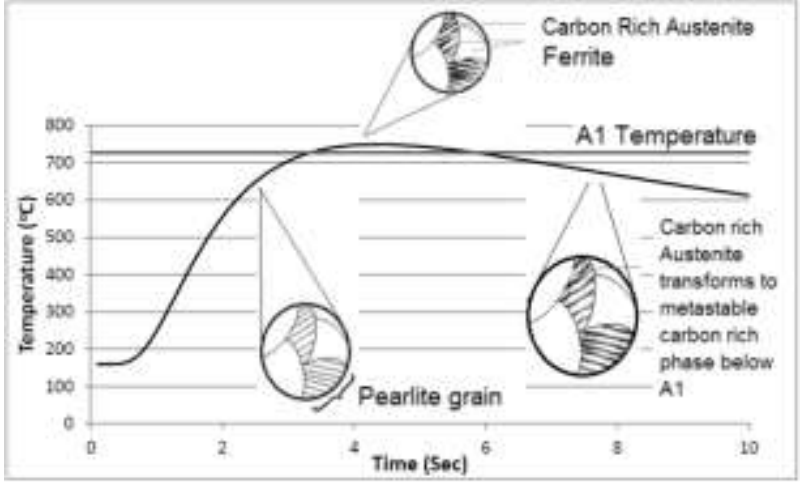

Figure 11: Temperature profile estimated using the thickplate Rosenthal equation at a distance of $12.6 \mathrm{~mm}$ from the heat source, using typical welding parameters.

Figure 11 demonstrates a typical welding cycle, at some distance from the heat source (in this case $12.6 \mathrm{~mm}$ ). In this case, material will experience a peak temperature of approximately $750^{\circ} \mathrm{C}$ and remain above the $A_{1}$ temperature (of about $723^{\circ} \mathrm{C}$, as estimated from the chemical composition [19]) for approximately 2.5 seconds.

The Rosenthal heat flow equation was used in combination with the maximum and minimum interpass temperatures allowable during the welding of the various joints done during this study in order to obtain the range of distances from the fusion line at which it would be reasonable to expect the formation of HAZ graphite. A range of heat inputs from 1 to $3 \mathrm{~kJ} / \mathrm{mm}$ was evaluated. The results can be seen in Figure 12. The results of these calculations were cross referenced with micrographs of service exposed material (see Figure 13) in order to verify that graphite is most likely to form in the intercritical HAZ.

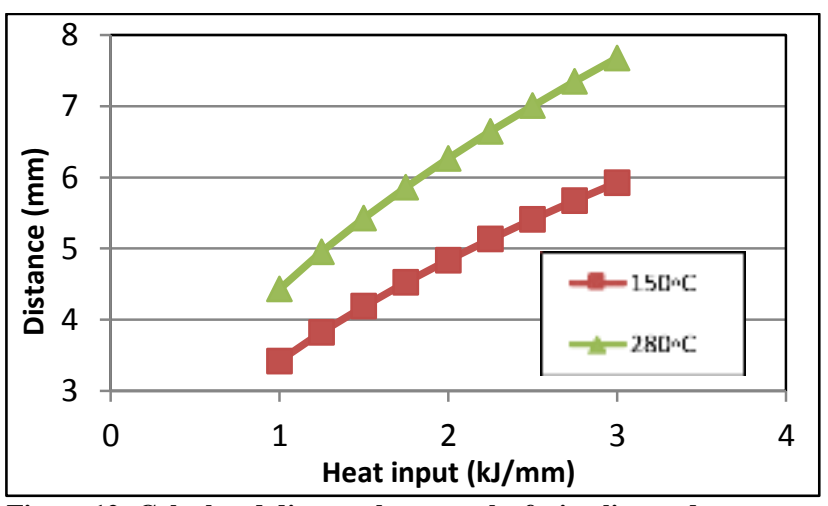

Figure 12: Calculated distance between the fusion line and $\mathrm{Ac}_{1}$ temperature for two preheat temperature(minimum preheat and maximum interpass) for a range of heat inputs. 


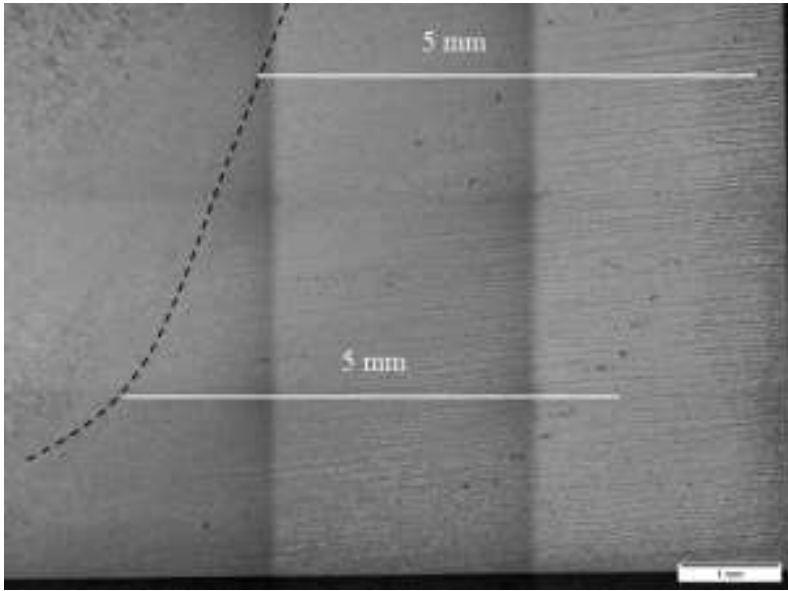

Figure 13: Micrograph of service exposed material

The quantitative metallography performed on a polished cross section of the intercritical HAZ indicated that the volume fraction of graphite is approximately $2.2 \%$. This is significantly higher than any other area in the material and indicates that there are favourable conditions for graphite formation and growth in these regions. Based on these findings, it can be concluded that if necking occurs in the HAZ, a crack that forms in the HAZ displays a strong preference towards cracking through the graphite which only contributes a small volume fraction of the total HAZ microstructure. It has been demonstrated that samples that fail through the HAZ follow a specific path that correlates strongly with the angle of the fusion line (See Figure 9 and Figure 10). Figure 10 also indicated that the graphite nodules appear to rupture in the direction that is parallel to the tensile load when the HAZ is observed in the through thickness direction of the pipe.

In an effort to estimate the percentage graphite that should be visible on a fracture surface if the material fails through the HAZ, the amount of graphite was measured using the following rationale. It has been observed that when a crack propagates through the HAZ, there are two distinct crack directions - the direction that is parallel to the tensile force and the direction that is perpendicular to the tensile force. (See, for example, Figure 10.) When the crack travels in the direction which is parallel to the tension force, it is observed that the crack is running along clusters of graphite nodules. Therefore, the ratio of crack length in the parallel direction to the total length of the crack should produce a similar percentage to the total graphite on the fracture surface as measured by the image analysis program. The results of these measurements indicated that the percentage graphite on the fracture surface in Figure 7 should be 59\%. This corresponded with data generated by image analysis that showed that the same fracture surface contained $55 \%$ graphite.
The relevance that this has to the percentage of graphite that is observed on the HAZ failure fracture surface is that, due to the step wise crack path, the original joint preparation will dictate the amount of graphite that is observed on the fracture surface. According to the geometry used in the current study, the amount of observed graphite should have been approximately $50 \%$ based on the 1 to 1 relationship between the horizontal length (graphite containing) and vertical length (graphite free) planes.

Figure 14 is a high magnification image of a graphite particle etched from the metallic substrate (4\% Nital for $5 \mathrm{~min}$ ). Figure 15 shows an inclusion which acted as the nucleation site from which graphite was able to grow from. These two images give insight into the highly irregular growth patterns of graphite as well as the fact that inclusions act as active nucleation sites.

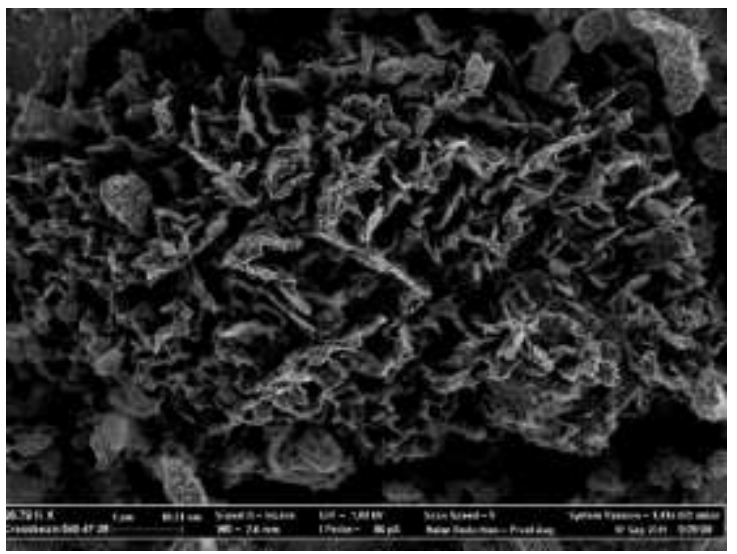

Figure 14: Complex structure of graphite inclusion, visible on an over-etched surface (high resolution SEM image, original magnification $26790 \mathrm{x}$ )

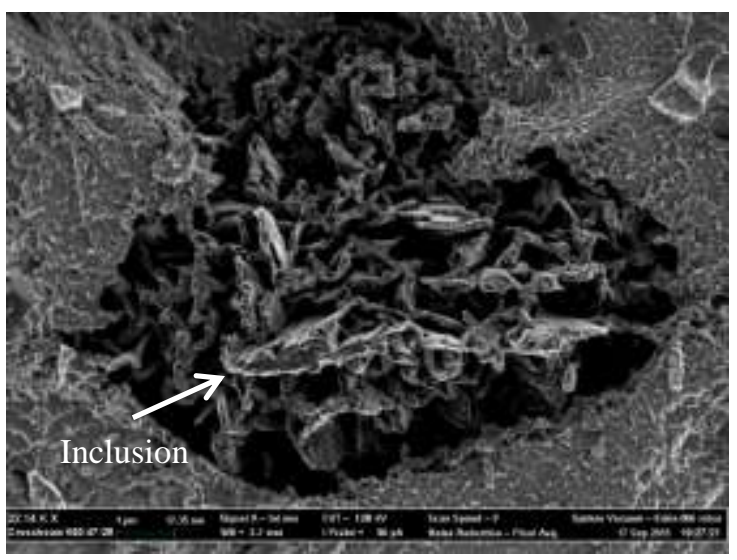

Figure 15: Nucleation site of graphite identified in base metal graphite

Based on the acceptable results for the tensile and bend tests, two procedure qualification records (PQRs) were developed as a result of these tests - 
one procedure for the partial penetration repair welds, and another for the double $\mathrm{V}$ joint.

\section{Conclusions}

- $\quad$ The presence of HAZ graphite observed in this study had no effect on the tensile properties that were tested, except for a decrease in reduction in area, when the tensile test coupon failed through the graphitized HAZ. All other mechanical tests resulted in the graphitized HAZ performing the same as the base metal.

- $\quad$ Prolonged heat treatment at $635^{\circ} \mathrm{C}$, at times up to 1200 hours, resulted in spheroidisation, but not in noticeable graphitisation. The prolonged heat treatments resulted in a reduction in tensile strength due to the severe spheroidisation that took place.

- The presence of graphite had no noticeable effect on weldability and repair welding on graphitized material can be performed successfully.

\section{References}

[1] Foulds J. R. and Viswanathan R. "Graphitization of steels in elevated-temperature service" Journal of materials engineering and performance, Vol 10 No 4, pp. 483-492, Aug. 2000.

[2] Meier A., Hammerschmidt D. and Skibbe E. "Graphitization effects on high temperature ductwork" Energytech, pp 5

[3] Samuals L.E. "Light Microscopy" pp 165-183

[4] Okada M. "Graphitization of weld heat-affected zone in carbon steel" Transaction of the Japan institute of metals. Pp 53 359

[5] Dennis, W. (1952). Heterogeneous Nucleation of Graphite in Hypo-Eutectoid Steel. Iron and Steel Instatute, 59-64.

[6] Harry, E. (1954). Subcritical decomposition of carbide phase in some low-carbon silicon steels. The Journal of the Iron and Steel Instatute, 109-112.

[7] Brown, F. (1954). Nucleation of Graphite in Steel. Welding Journal, 257-261.

[8] He, K. (2007). An electron microscopic study of spheroidal graphite nodules formed in a medium-carbon steel by annealing. Acta Materialia, 2919-2927.

[9] Graphitization of Weld Heat-Affected Zone in Carbon Steel. Okada, Minoru. 1982, Transaction of the Japan Institute of Metals, pp. 353-359.

[10] Heterogeneous Nucleation of Graphite in Hypo-Eutectoid Steel. Dennis, W.E. 1952, Iron and Steel Instatute, pp. 59-64. [11] Bharadwaj, Maneel. Study of Graphitization in Carbon Steel Weldments for Remaining Life Assessment. Knoxville : s.n., 14 November 2016.

[12] Foulds J. R. and Shingledecker J.P. "An updated assessment of graphitization of steels in elevated temperature service" Journal of materials engineering and performance, Vol 24 No 2, pp. 586-597, Dec. 2014.

[13] ASM Handbook Volume 11. Failure Analysis and Prevention. ASM International 2002, p.693.

[14] An Updated Assessment of Graphitization of Steels in Elevated Temperature Service. Foulds, J and Shingledecker, P. 2015, Journal of Materials Engineering and Performance, pp. 586-597.
[15 ] Thielsch, Helmut. Interpreting Graphitization. Rhode Island : Grinnell Company, 1954

[16] 2013 ASME Boiler and Pressure Vessel Code. IX Welding, Brazing and Fusing Qualifications.

[17] Toft, L., \& Marsden, R. (1963). The Structure and Properties of $1 \% \mathrm{Cr}-0.5 \% \mathrm{Mo}$ Steel. The Iron and Steel Instatute, 276-294.

[18] K Easterling, Introduction to the Physical Metallurgy of Welding. Second Edition pp.18-30.

[19] Leslie, William. The Physical Metallurgy of Steels. Michigan : McGraw-Hall International Book Company, 1981. 